UCRL-JC-132262

\title{
Characterization of Multilayer Reflective Coatings for Extreme Ultraviolet Lithography
}

\author{
Marco Wedowski, Eberhard A. Spiller, Claude Montcalm, Patrick A. Kearney, \\ Sasa Bajt, Mark A. Schmidt, James A. Folta \\ Lawrence Livermore National Laboratory, Livermore, CA 94551 \\ Eric m. gullikson, James h. Underwood \\ Lawremce Berkeley National Laboratory, Berkeley, CA94720
}

11 th US National Synchrotron Radiation Instrumentation Conference

October 13-15, 1999

Stanford, CA

November 1, 1999

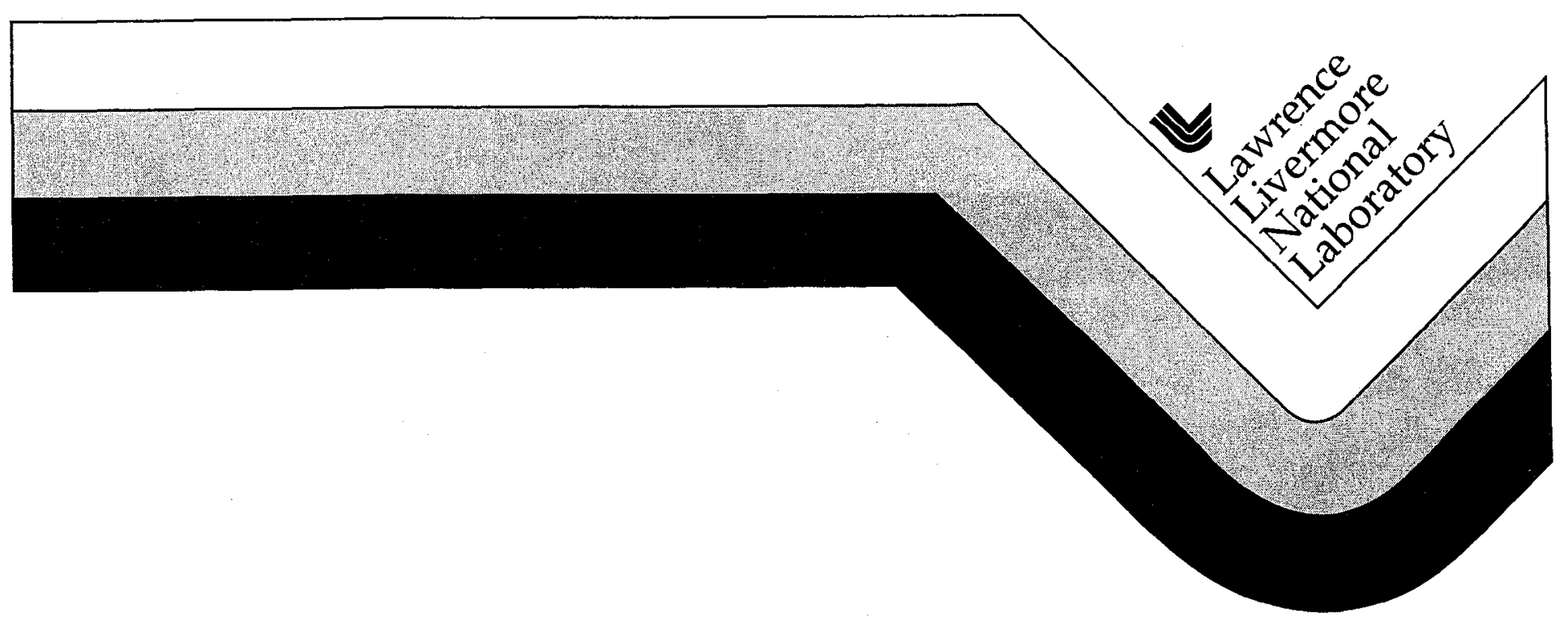




\section{DISCLAIMER}

This document was prepared as an account of work sponsored by an agency of the United States Government. Neither the United States Government nor the University of California nor any of their employees, makes any warranty, express or implied, or assumes any legal liability or responsibility for the accuracy, completeness. or usefulness of any information, apparatus, product, or process disclosed, or represents that its use would not infringe privately owned rights. Reference herein to any specific commercial products, process, or service by trade name, trademark, manufacturer, or otherwise, does not necessarily constitute or imply its endorsement, recommendation, or favoring by the United States Government or the University of California. The views and opinions of authors expressed herein do not necessarily state or reflect those of the United States Government or the University of Califomia, and shall not be used for advertising or product endorsement purposes. 


\title{
Characterization of Multilayer Reflective Coatings for Extreme Ultraviolet Lithography
}

\author{
Marco Wedowski*i, Eric M. Gullikson ${ }^{\dagger}$, James H. Underwood ${ }^{\dagger}$, \\ Eberhard A. Spiller*, Claude Montcalm*, Patrick A. Kearney*, S. Bajt*, \\ Mark A. Schmidt*, James A. Folta* \\ *Lawrence Livermore National Laboratory, Information Science \& Technology, Livermore, CA 94550 \\ ${ }^{\dagger}$ Lawrence Berkeley National Laboratory, Center for X-Ray Optics, Berkeley, CA 94720
}

\begin{abstract}
The synchrotron-based reflectometer at beamline 6.3.2 of the Advanced Light Source (ALS) in Berkeley is an important metrology tool within the current Extreme Ultraviolet Lithography (EUVL) program. This program is a joint activity of three National Laboratories and a consortium of leading semiconductor manufacturers. Its goal is the development of a technology for routine production of sub-100 $\mathrm{nm}$ feature sizes for microelectronic circuits. Multilayer-coated normal-incidence optical surfaces reflecting in the Extreme Ultraviolet (EUV) spectral range near $13 \mathrm{~nm}$ are the basis for this emerging technology. All optical components of EUV lithographic steppers need to be characterized at-wavelength during their development and manufacturing process. Multilayer coating uniformity and gradient, accurate wavelength matching and high peak reflectances are the main parameters to be optimized. The mechanical and optical properties of the reflectometer at ALS beamline 6.3.2 proved to be well suited for the needs of the current EUVL program. In particular the facility is highly precise in its wavelength calibration and the determination of absolute EUV reflectance. The reproducibility of results of measurements at ALS beamline 6.3 .2 is $0.2 \%$ for reflectivity and $0.002 \mathrm{~nm}$ for wavelength.
\end{abstract}

\section{INTRODUCTION}

Multilayer reflective coatings for the EUV spectral range have been under development at Lawrence Livermore National Laboratory (LLNL) for more than 10 years. Initially the high-precision characterization of their reflective properties was performed at the radiometry laboratory of Physikalisch-Technische Bundesanstalt (PTB) at BESSY in Berlin ${ }^{1,2,3}$. In 1996 the standards and calibration beamline 6.3.2 at the Advanced Light Source (ALS) in Berkeley ${ }^{4}$ became available and has been used to characterize LLNL EUV multilayer coatings. Today the EUVL program utilizes up to $50 \%$ of the available beamtime for multilayer characterizations at ALS beamline 6.3.2.

High precision reflectometry provides important data for the manufacturing of components for Extreme Ultraviolet Lithography. Several areas of the EUVL program make use of the unique features of beamline 6.3.2: $\mathrm{Mo} / \mathrm{Be}$ multilayer development ${ }^{5}$, radiation stability assessment ${ }^{6}$, optics coating ${ }^{7,8,9}$, mask blank development ${ }^{10}$, as well as the qualification of patterned masks ${ }^{11}$. 
Utilizing ALS beamline 6.3.2, significant progress has been made on general aspects of the development of multilayer reflective coatings ${ }^{12,13}$. In particular the temporal stability, normal incidence reflectance and stress of multilayers for EUVL have been investigated. This early phase was followed by the manufacturing phase of optical components for the Engineering Test Stand (ETS) prototype EUVL tool. The manufacturing phase required a dramatic increase in the quantity of data obtained at ALS beamline 6.3.2, while maintaining its quality on the same high level as achieved earlier. Another new requirement was the appropriate timing of the delivery of samples to the beamline and the return of data from the beamline. ALS beamline 6.3.2 served the needs of the EUVL program to the fullest extent.

\section{EXPERIMENTAL}

\section{Beamline Features}

The details of ALS beamline 6.3.2 are thoroughly described elsewhere ${ }^{4}$. High spectral purity of the radiation delivered is obtained with a 3-mirror higher order suppressor. High resolution and high throughput of the beamline is achieved with a VLS-PGM monochromator. Pump down times are on the order of 20 minutes due to the use of a cryo pump in combination with a differentially pumped section near the monochromator. Samples ranging in size from a few millimeters to $200 \mathrm{~mm}$ in diameter and weighing up to $10 \mathrm{~kg}$ can be routinely positioned relative to the EUV beam with a spatial precision of $0.1 \mathrm{~mm}$ and an angular precision of $0.01^{\circ}$. For this purpose two rotational stages and a variety of fixtures are available. Finally, raw data obtained with a LabView program running on a SUN workstation can be immediately processed on a beamline PC using EXCEL and IDL routines.

\section{Experimental Procedures}

Any precision manufacturing of EUVL components involving multilayer reflective coatings requires reliable fecdback on the result of a particular process step. Multilayer coating uniformity and gradient, accurate wavelength matching and high peak reflectances are the main parameters to be optimized. These parameters are important for high EUV transmission and for the preservation of the optical wavefront in the final EUVL optical system. In order to enable quick convergence of the above mentioned iterative feedback loop, all experimental procedures at ALS beamline 6.3.2 are especially designed for a short turn-around time and high reliability of the data.

Typically reflectance curves are manually measured near the center of the samples. However, for the determination of profiles, automatic scans across the sample surfacc are performed. At each point of a scanned region full reflectance curves are obtained and the peak reflectance, peak position and bandwidth are determined. Other experimental modes include the spatial mapping at a fixed wavelength. 


\section{Measurement Precision}

Much effort has been made to ensure the accuracy of the data obtained at ALS beamline 6.3.2 and at PTB's SX700 beamline. Since both beamlines derive their calibration from first principles independently, comparison experiments between the two beamlines were performed in $1996^{4}$. Although this comparison already yielded satisfactory agreement for reflectance and wavelengths, it still appeared desirable to repeat measurements at both facilities. Results on a graded standard $\mathrm{Mo} / \mathrm{Si}$ multilayer reflective coating deposited at LLNL are summarized in table 1.

TABLE 1. Comparison of profiling results obtained at ALS beamline 6.3.2 and PTB's SX700 Position: $x=-1 \mathbf{~ m m}$ Position: $\mathrm{x}=\mathbf{0}$ Position: $x=1$

Sample: M1980416 A-B

Fused silica 1" GO flat

PTB $(y=-1 \mathrm{~mm}): 13.427 \mathrm{~nm}$

$\operatorname{ALS}(\mathbf{y}=-1 \mathrm{~mm}): 13.428 \mathrm{~nm}$
PTR (y= $1 \mathrm{~mm}): 13.429 \mathrm{~nm}$ $\operatorname{ALS}(\mathrm{y}=1 \mathrm{~mm}): 13.430 \mathrm{~nm}$

PTB (y=0 mm): $13.427 \mathrm{~nm}$ ALS (y=0 mm): $13.428 \mathrm{~nm}$

PTB $(\mathrm{y}=-1 \mathrm{~mm}): 13.425 \mathrm{~nm}$ ALS (y= -1 mm): $13.426 \mathrm{~nm}$
Center FWHM at normal inc.

PTB (y= $1 \mathrm{~mm}): 13.427 \mathrm{~nm}$

$\operatorname{ALS}(\mathbf{y}=\mathbf{1} \mathbf{m m}): 13.427 \mathrm{~nm}$

The wavelength gradient on the order of $0.002 \mathrm{~nm} / \mathrm{mm}$ along the y direction is consistently revealed in measurements at both facilities. Both data sets deviate systematically by only $0.001 \mathrm{~nm}$. PTB data is derived from the calibration certificate ${ }^{14}$ issued for measurements performed on sample M1980416 A-B.

Reflectance values on a number of samples were recently found to be consistently within $0.2 \%$ when measured at both facilities. However, a newly cleaved piece of reference coating M1960821A2 this time yielded $66.4 \%$ at PTB, while later $66.1 \%$ were obtained at the ALS. This is the opposite of earlier reported $66.1 \%$ for measurements at PTB and $66.5 \%$ for measurements at the ALS. The conclusion is that this sample suffers from surface contamination during repeated handling as a reference sample. Lower values are consistently achieved after repeated use. Already a monolayer of surface contamination may cause a reflectance loss on the order of $0.5 \%$.

\section{ACKNOWLEDGMENTS}

This work was performed under the auspices of the U. S. Department of Energy by the Lawrence Livermore National Laboratory under Contract No. W-7405-ENG-48. Funding was provided by the Extreme Ultraviolet Limited Liability Company (EUV LLC) under a Cooperative Research and Development Agreement (CRADA).

The work performed at LBNL is supported through a CRADA with the Extreme Ultraviolet Limited Liability Company (EUV LLC) and by the U.S. Department of Energy, under contract No. DE-AC03-76F00098. 


\section{REFERENCES}

1. Ulm, G., and Wende, B., "Radiometry Laboratory of Physikalisch-Technische Bundesanstalt at BESSY", Rev. Sci. Instrum. 66 (2), 2244-2247 (1995).

2. Scholze, F., Krumrey, M., Müller, P., and Fuchs, D., "Plane Grating monochromator beamline for VUV radiometry", Rev. Sci. Instrum. 65 (10), 3229-3232 (1994).

3. Fuchs, D., Krumrey, M., Müller, P., and Ulm, G., "High precision soft x-ray reflectometer", Rev. Sci. Instrum. 66 (2), 2248-2250 (1995).

4. Underwood, J. H., and Gullikson, E. M. "High-resolution, high-flux, user friendly VLS beamline at the ALS for the 50-1300 eV energy region", J.Electr.Spectrosc.Relat.Phenom. 92, 265-272 (1998).

5. Bajt, S., Behymer, R. D., Mirkarimi, P. B., Montcalm, C., Wall, M. A., Wedowski, M., Folta, J. A., "Experimental investigation of beryllium-based multilayer coatings for extreme ultraviolet lithography", in EUV, X-Ray and Neutron Optics and Sources, Carolyn A. MacDonald, Editor, Proceedings of SPIE Vol. 3767 (1999).

6. Wedowski, M., Bajt, S., Folta, J. A., Gullikson, E. M., Kleineberg, U., Klebanoff, L. E., Malinowski, M. E., Clift, W. M., "Lifetime Studies of $\mathrm{Mo} / \mathrm{Si}$ and $\mathrm{Mo} / \mathrm{Be}$ multilayer coatings for extreme ultraviolet lithography", in EUV, X-Ray and Neutron Optics and Sources, Carolyn A. MacDonald, Editor, Proceedings of SPIE Vol. 3767 (1999).

7. Montcalm, C., Spiller, E. A., Wedowski, M., Gullikson, E. M., Folta, J.A., "Multilayer coatings of 10x projection optics for extreme-ultraviolet lithography" in Emerging Lithographic Technologies III, Yuli Vladimirski, Editor, Proceedings of SPIE Vol. 3676, 710-716 (1999).

8. Folta, J. A., Bajt, S., Barbee, T. W. Jr., Grabner, R. F., Mirkarimi, P. B., Nguyen, T., Schmidt, M. A., Spiller, E. A., Walton, C. C., Wedowski, M., and Montcalm, C., "Advances in multilayer reflective coatings for extreme ultraviolet lithography" in Emerging Lithographic Technologies III, Yuli Vladimirski, Editor, Proceedings of SPIE Vol. 3676, 702-709 (1999).

9. Montcalm, C., Grabner, R. F., Hudyma, R. M., Schmidt, M.A., Spiller, E.A., Walton, C. C., Wedowski, M., Folta, J.A., "Multilayer coated optics for an alpha-class extreme ultraviolet lithography system", in EUV, X-Ray and Neutron Optics and Sources, Carolyn A. MacDonald, Editor, Procecdings of SPIE Vol. 3767 (1999).

10. Burkhart, S., Cerjan, C., Kearney, P., Mirkarimi, P., Walton, C. and Ray-Chaudhuri, A., "Lowdefect reflective mask blanks for Extreme Ultraviolet Lithography" in Emerging Lithographic Technologies III, Yuli Vladimirski, Editor, Proceedings of SPIE Vol. 3676, 570-577 (1999).

11. Yan, P., Zhang, G., Kofron, P., Chow, J., Stivers, A., Tejnil, E., Cardinale, G. and Kearney, P., "EUV Mask patterning approaches" in Emerging Lithographic Technologies III, Yuli Vladimirski, Editor, Proceedings of SPIE Vol. 3676, 309-313 (1999).

12. Montcalm, C., Bajt, S., Mirkarimi, P. B., Spiller, E. A., Weber, F. J., Folta, J. A., "Multilayer reflective coatings for extreme-ultraviolet lithography" in Emerging Lithography Technologies II, Yuli Vladimirski, Editor, Proceedings of SPIE Vol. 3331, 42-51 (1998).

13. Mirkarimi, P.B., "Stress, reflectance, and temporal stability of sputter-deposited $\mathrm{Mo} / \mathrm{Si}$ and $\mathrm{Mo} / \mathrm{Be}$ multilayer films for extreme ultraviolet lithography", Opt. Eng. 38 (7), 1246-1259 (1999).

14. Ulm, G., Schmitz, D., "Calibration certificate for extreme-ultraviolet $\mathrm{Mo} / \mathrm{Si}$ multilayer mirrors coated at LLNL", Physikalisch-Technische Bundesanstalt, Braunschweig und Berlin, Reference No. PTB 7.12-200/98. 